\title{
SHORT COMMUNICATION 1.8 GHz Lumped Component Thick Film Amplifier
}

\author{
C. P. ALLEN, C. E. TUCKER and K. W. WOODCOCK
}

Brighton Polytechnic, Brighton, Sussex, U.K.

and

P. G. BARNWELL

Eurotherm Ltd, Worthing, Sussex, U.K.

(Received June 18, 1974)

\section{INTRODUCTION}

Until recently Microwave Integrated Circuits (MIC) have invariably been of the distributed component type; that is, active and passive components are added to a substrate upon which there are distributed components. Distributed components, by definition, have dimensions that are comparable to the wavelength of operation, while lumped components must be much smaller than a wavelength. At low microwave frequencies, distributed components limit the miniaturisation of MIC's; thus for small circuits lumped components must be used. Until recently lumped components were normally only used below $500 \mathrm{MHz}$ but Aitchison ${ }^{1}$ has demonstrated their use at frequencies into $\mathrm{X}$ band. These circuits, as are most MIC's, were fabricated using thin film techniques which, due to the etching process involved, allow very fine lines but with high processing costs. Therefore it was decided to investigate the fabrication of thick film lumped microwave components.

\section{BASIC PRINCIPLES}

Although considerable experience has been gained of high $\mathrm{Q}$ inductors and capacitors ${ }^{2}$ at frequencies up to $250 \mathrm{MHz}$, further investigation was necessary to ascertain whether these techniques are applicable at microwave frequences. The measurement of lumped components at these frequencies is difficult and is one reason why they are little used. As it is not possible to obtain a near perfect inductor or capacitor at microwave frequencies, a method capable of determining both the equivalent capacitance and inductance is useful. Such a method is that used by Aitchison. ${ }^{1}$ In this, the impedence of a parallel $L C$ circuit is measured about resonance. Then, at resonance:

$$
C=\frac{1}{2} \cdot \frac{\mathrm{d} B}{\mathrm{~d} \omega}
$$

where $B=$ susceptance, and $\omega=$ angular frequency. From this the inductance can be readily calculated.

Test circuits of the form shown in Figure 1 were printed and measured. A microstrip launcher was used to connect directly into the circuit, while a

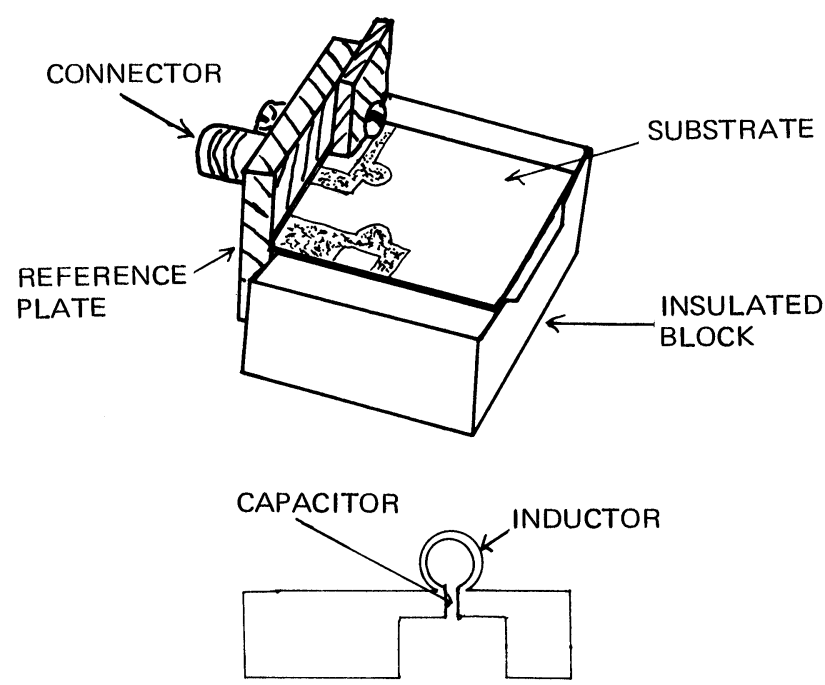

FIGURE 1 Component test jig and resonant test circuit. 


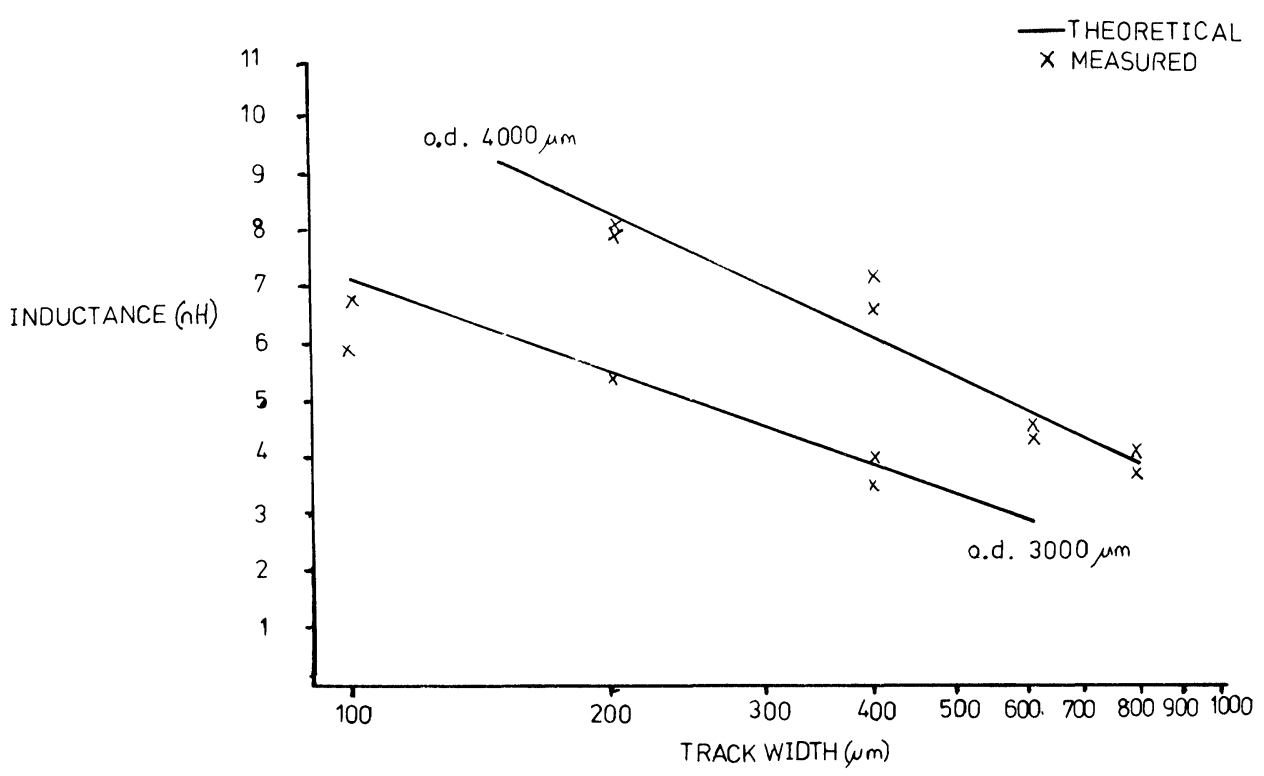

FIGURE 2 Relation between inductance, outside diameter and track width, for single loop inductors.

shorting bar connected to the plate holding the launcher made the ground contact. A reference plane was obtained by adjusting the shorting bar so that it connected to the launcher centre tab. This method has the advantage that the block can be made of an insulating material to reduce strays. The circuit impedance was measured for a number of frequencies either side of resonance using a slotted line. These were then plotted on a Smith chart and the capacit- ance, and hence inductance, calculated from Eq. (1). Inductors with two outside diameters and five different track widths were measured and the results are shown in Figure 2. These compare well with the theoretical values obtained using Grover's ${ }^{3}$ formula, which has been found to give accurate results at VHF. $^{2}$

As capacitor values of interest are of the order of $1 \mathrm{pF}$, it was decided to use interdigitated capacitors,

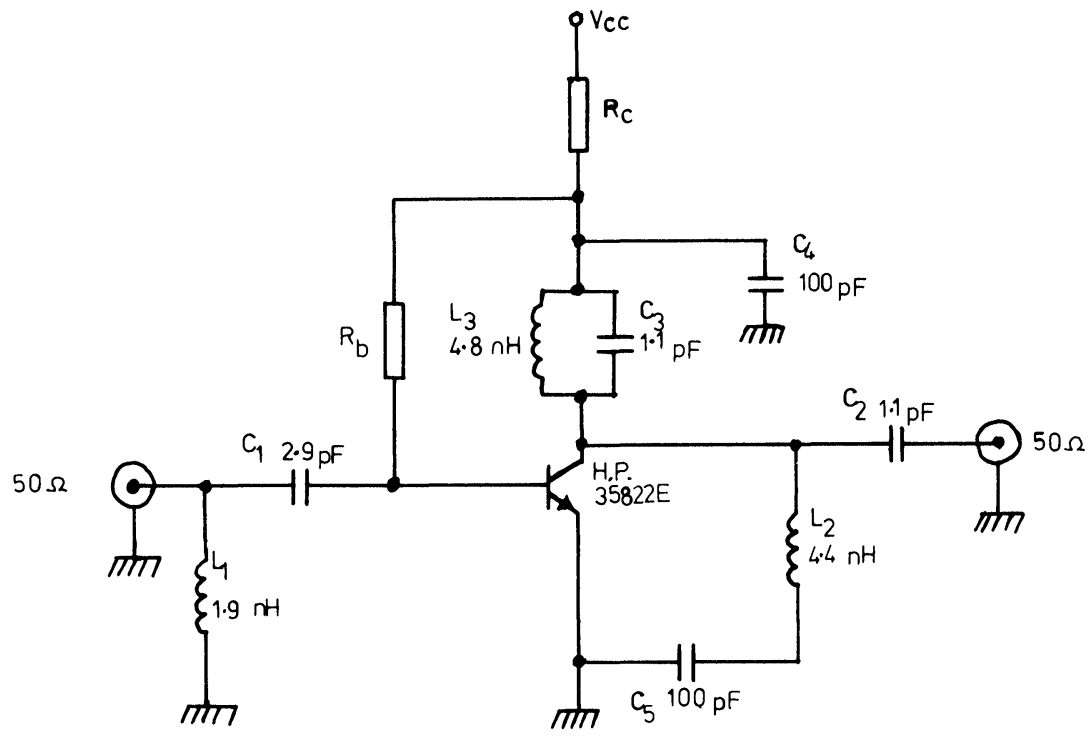

FIGURE 3 Amplifier circuit diagram. 
as these had previously been found to have low loss and well-defined capacitance. The theoretical analysis of the interdigitated capacitor is extremely complex and measurements at lower frequencies indicate that standard analyses, that do not take into account the conductor thickness, lead to very large errors. As a result, empirical methods were used to design the capacitors required, using previously obtained results. $^{4}$

\section{DESIGN AND MANUFACTURE}

An amplifier was designed using these lumped components to operate at $1.8 \mathrm{GHz}$, this being a frequency of considerable potential application. The transistor used had to be in a form suitable for attachment to thick film conductors and be completely characterised at the frequency of operation. The HewlettPackard type 35822 was selected as meeting these requirements. To improve stability and to lower transistor noise, the common emitter connection was employed, as shown in the circuit diagram of Figure 3. $L$-type input and output matching networks were used, consisting of $L_{1}, C_{1}$ and $L_{2}, C_{2}$. As it was not desired to operate the amplifier over a large bandwidth, this simple technique was applicable and had the added advantage of isolating bias voltages.

The values of $C_{4}$ and $C_{5}$ necessitate their being made as conventional overlay screened and fired capacitors, but as they are not in the signal path, losses within them are insignificant. Stray capacitance and inductance can have considerable effect on the performance of a microwave amplifier and care must be taken when designing the layout. To reduce inductance in the emitter circuit, the transistor is provided with two emitter leads. It is essential that these leads are well connected to the ground plane if feedback and instability problems are to be avoided. In order to minimise coupling effects between input and output circuits, they should be separated by an area of ground plane, which should also surround the components. Using these design rules, the circuit was laid out on a $25.4 \mathrm{~mm} \times 25.4 \mathrm{~mm} \times 0.635 \mathrm{~mm} 96 \%$ alumina substrate, as in Figure 4. By having a short microstrip line at the output, it was possible to run a ground plane on part of the reverse side of the substrate, further reducing strays.

It should be noted that $L_{1}$ is so small that a ribbon inductor has been used. This can be easily adjusted using an air-abrasive trimmer for optimum matching.

Six screens were needed for the amplifier, consist-

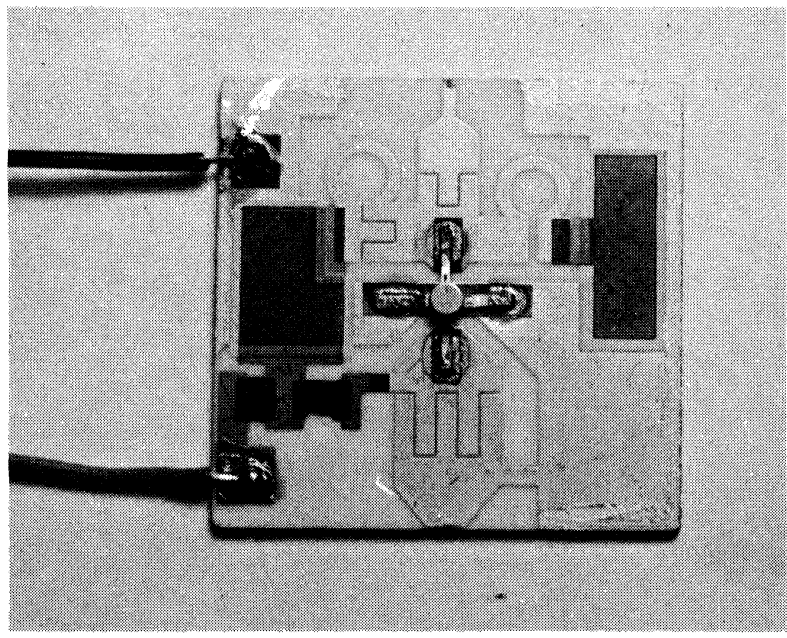

FIGURE 4 Complete amplifier on 1" $\times 1$ 1" substrate.

ing of three conductor patterns, two resistor patterns and one dielectric pattern.

The ground plane was connected to the earths on the top of the substrate by applying silver loaded epoxy to the appropriate edges. Resistors were trimmed before device attachment on the basis of the measured current gain of the transistor, which was attached by depositing low melting point soldercream and reflow soldering.

\section{RESULTS}

The performance of the circuit was measured using a Hewlett-Packard Network Analyser and the gainfrequency response is shown in Figure 5. To test the repeatability of the thick film circuit and the spread in transistor parameters, a second circuit was built. There was no significant difference between their performance. The gain was found to be $8.4 \mathrm{~dB}$ compared with a theoretical figure of $10.8 \mathrm{~dB}$. This lower measured value is probably due to $S$ parameter variations and losses in the matching networks. An input VSWR of 1.2 was found at $1.8 \mathrm{GHz}$ but the output circuit value was 5 . The peak in gain occurred at a frequency of $1.66 \mathrm{GHz}$ as $C_{3}$ had been made large in order that exact adjustment could be made by trimming.

A considerable amount of further development remains to be carried out, but this initial programme demonstrates conclusively the feasibility of using lumped thick film components up to at least $2 \mathrm{GHz}$. 


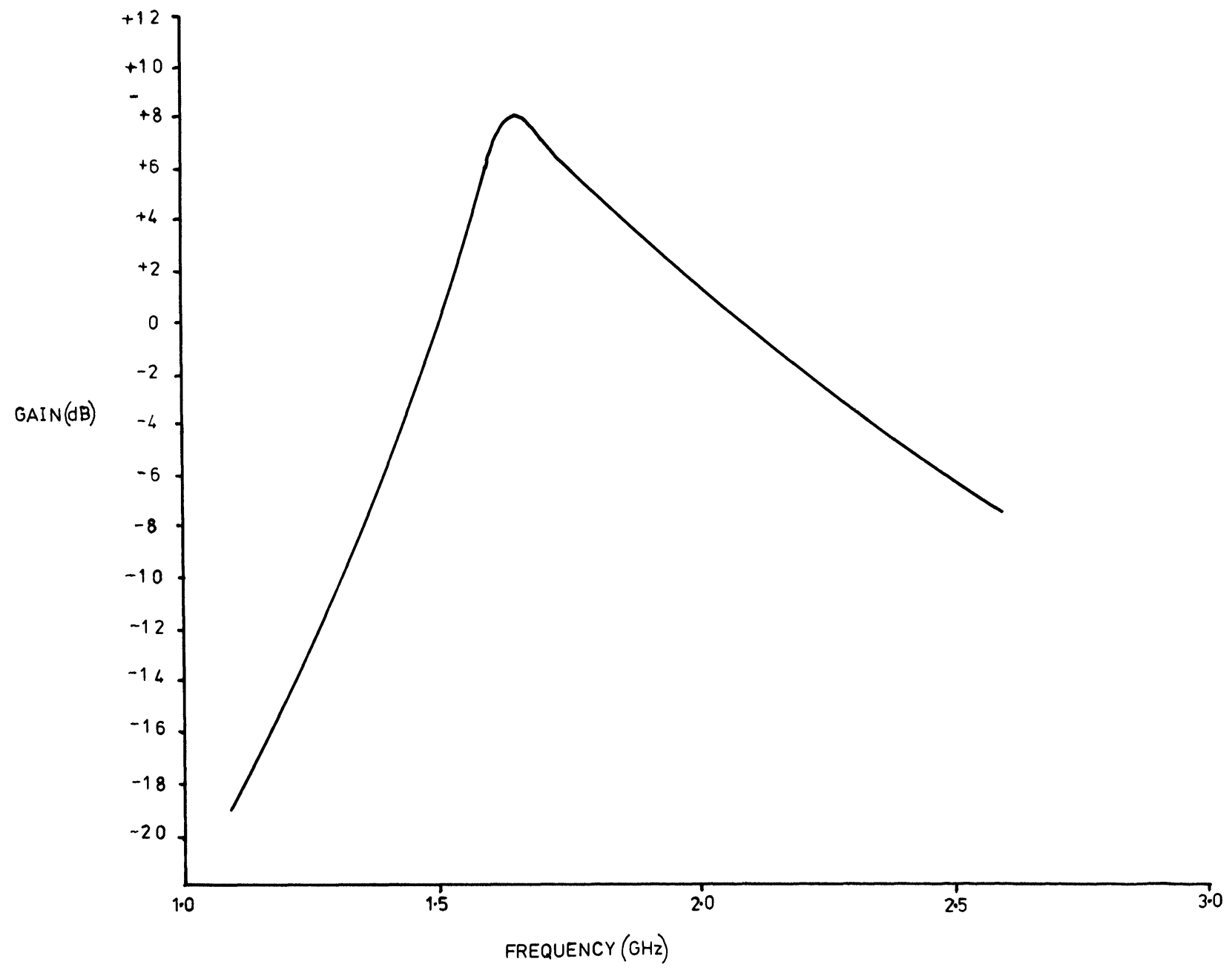

FIGURE 5 Gain-frequency response.

\section{ACKNOWLEDGEMENT}

The authors wish to express their appreciation to Dr. B. H. Venning, Head of the Electrical and Electronic Engineering Department, Brighton Polytechnic, for his support and encouragement and to the University of Sussex for the loan of some microwave equipment.

\section{REFERENCES}

1. C. S. Aitchison, "Lumped circuit elements at microwave frequencies." IEEE Trans. Microwave Theory Tech. 19, 928 (1971).

2. P. G. Barnwell, and C. E. Tucker, "The radio frequency properties of thick film components." Conference on Hybrid Microelectronics, September 1973. IERE Conference Proceedings, No. 27, pp. 173-189. (1973).

3. F. W. Grover, Inductance Calculations (Dover, New York 1962).

4. C. E. Tucker, and P. G. Barnwell, "Interdigitated capacitors." Electronic Components, 14, 163 (1973). 

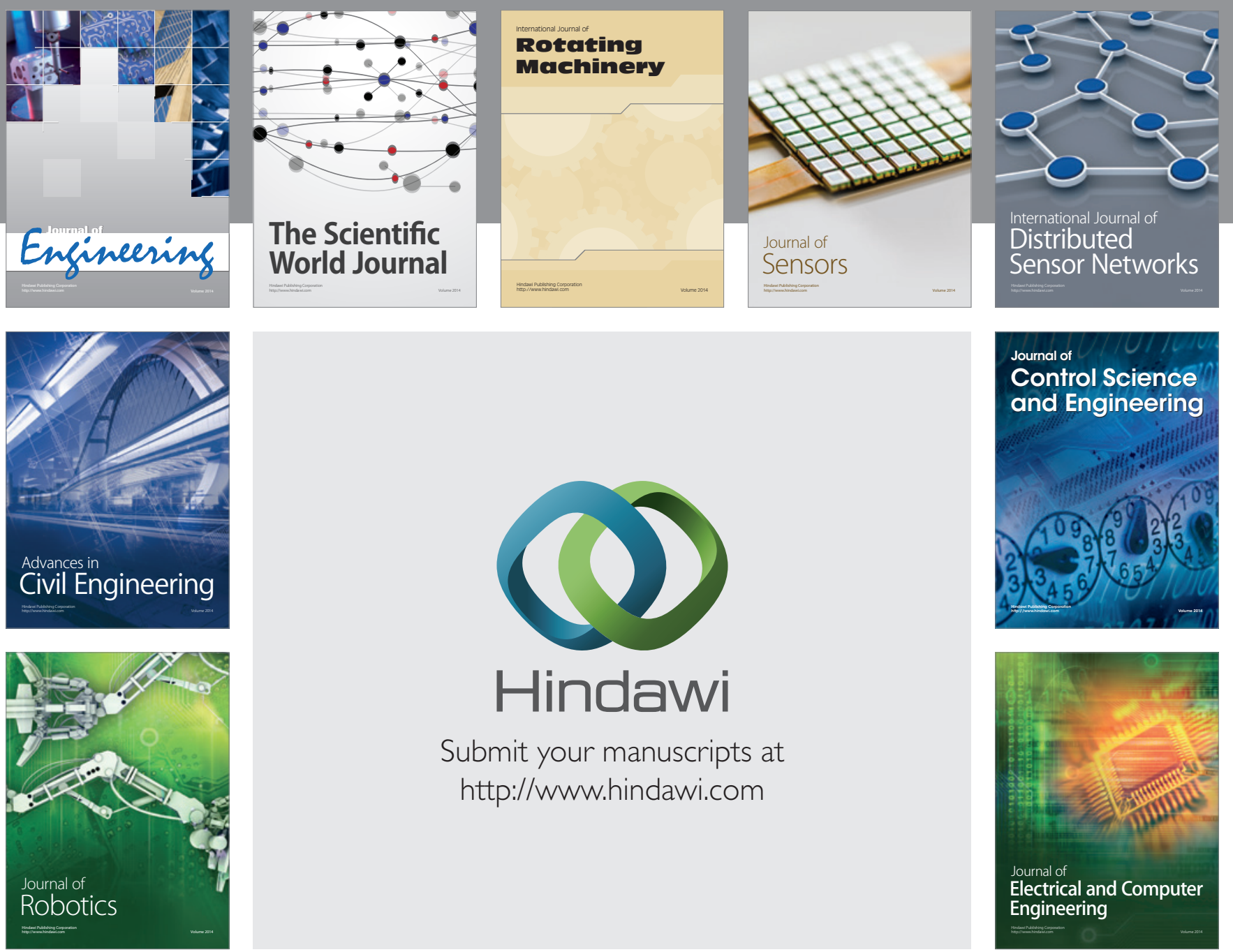

Submit your manuscripts at

http://www.hindawi.com
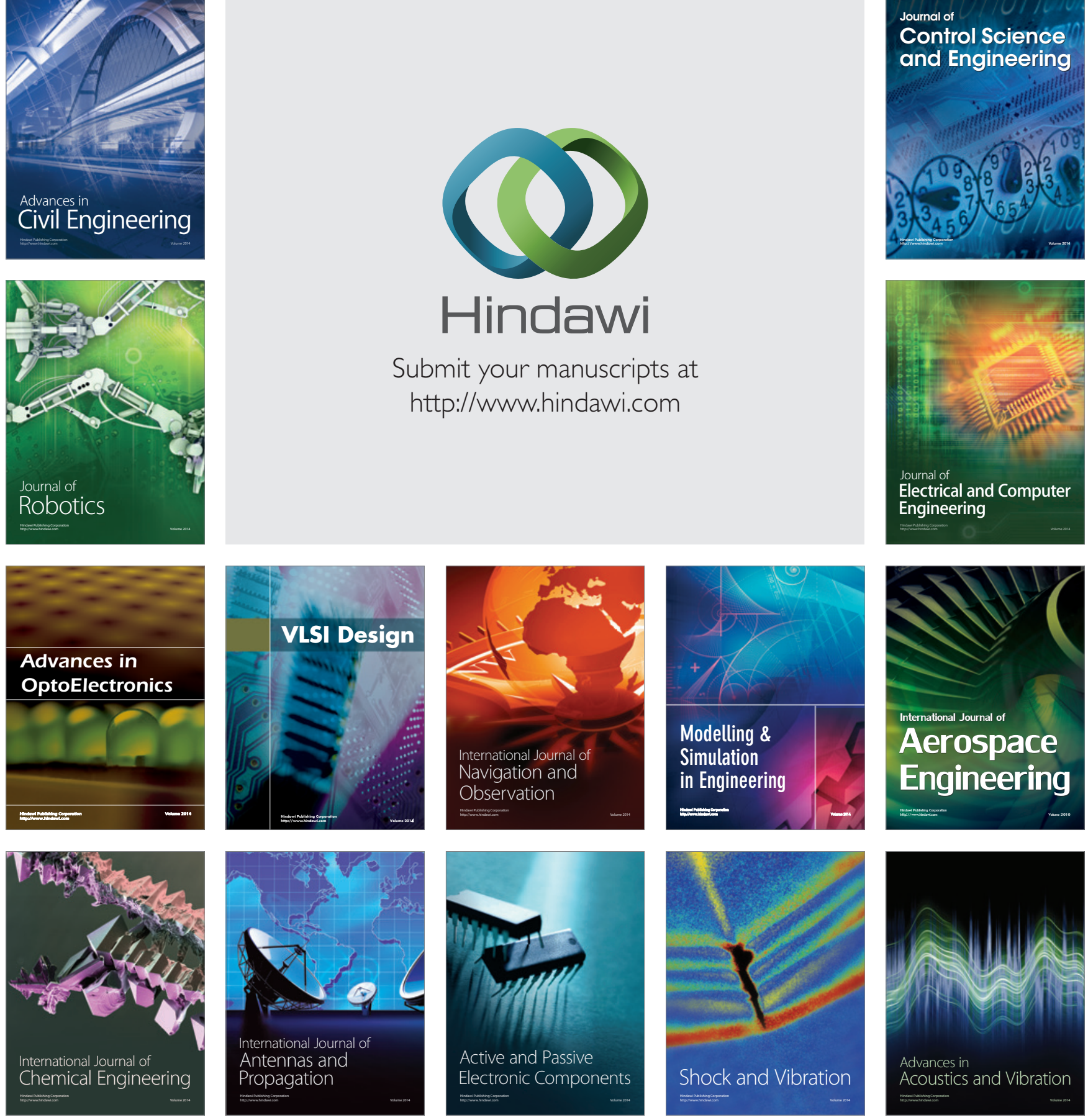